\title{
Variations in compliance with starchy food recommendations and consumption of types of starchy foods according to sociodemographic and socioeconomic characteristics
}

\author{
Mathilde Touvier $^{1}{ }^{*}$, Caroline Méjean ${ }^{1}$, Emmanuelle Kesse-Guyot ${ }^{1}$, Anne-Claire Vergnaud ${ }^{1}$, \\ Sandrine Péneau ${ }^{1}$, Serge Hercberg ${ }^{1,2,3}$ and Katia Castetbon ${ }^{2}$ \\ ${ }^{1}$ Unité de Recherche en Epidémiologie Nutritionnelle (UREN), UMR U557 Inserm/U1125 Inra/Cnam/Paris 13, CRNH IdF, \\ SMBH Paris 13, 74 rue Marcel Cachin, F-93017 Bobigny Cedex, France \\ ${ }^{2}$ Unité de Surveillance et d'Epidémiologie Nutritionnelle (USEN), Institut de Veille Sanitaire, Université Paris 13, \\ 74 rue Marcel Cachin, F-93017 Bobigny Cedex, France \\ ${ }^{3}$ Département de Santé Publique, Hôpital Avicenne, F-93017 Bobigny Cedex, France
}

(Received 1 June 2009 - Revised 27 October 2009 - Accepted 11 November 2009 - First published online 9 December 2009)

Nutritional recommendations call for balanced, diversified consumption of starchy foods and increased whole-grain food intake. Their efficiency may depend on sociodemographic and socioeconomic factors, for which little information is available. The aim of the present study was to investigate the relationship between sociodemographic and socioeconomic characteristics and starchy food consumption in a large general population of French adults. Dietary intake was assessed using at least six 24-h dietary records collected, during a 2-year period, from 4574 men and women aged 45-60 years who participated in the Supplémentation en VItamines Minéraux et AntioXydants cohort study in 1995-7. Compliance with the recommendation ( $\geq 3$ and $<6$ servings/d), non-consumption of whole-grain products, variety and daily cost were compared across sociodemographic and socioeconomic categories using logistic regression and covariance analyses. About $55 \%$ of subjects complied with the starchy food recommendation, with little variation across sociodemographic characteristics. Consumption of whole-grain products was less likely in men $(P=0.001)$, in subjects with a lower education level $(P$-trend $=0.01)$ and in those belonging to intermediate occupational categories $(P=0.02)$. The variety of starchy food intake increased with education level $(P$-trend $=0.0002)$ and was lowest for manual workers $(P=0 \cdot 03)$. The proportion of daily food cost spent on starchy foods decreased with occupational category $(P<0 \cdot 0001)$, and was higher in rural areas $(P=0.0004)$. The starchy food budget spent on potatoes decreased with the educational level $(P$-trend $=0.007)$, whereas it increased for rice and unsweetened breakfast cereals $(P$-trend $=0.001$ for both). Public recommendations concerning starchy food variety and whole-grain intake should specifically target subjects with a lower education level and/or occupational category.

Starchy foods: Whole-grain foods: Sociodemographic factors: Socioeconomic factors

Starchy foods are good sources of complex carbohydrates. Within this food group, whole-grain products are rich in fibres and carry various micronutrients. Epidemiological evidence suggests that higher consumption of whole-grain foods could significantly reduce the risk of chronic diseases such as CVD, type 2 diabetes and certain cancers ${ }^{(1-3)}$. Therefore, balanced and diversified consumption of starchy foods, especially whole-grain products, is a major objective of current nutritional public health policies ${ }^{(4)}$. In France, the 2001-10 French Nutrition and Health Programme (Programme National Nutrition Santé) is being backed up by a large-scale national communications campaign and widespread diffusion of guides. It targets nine nutritional recommendations ${ }^{(5,6)}$. Starchy food is one of these, with the benchmark being 'at each meal, according to appetite' for starchy foods in general, and an additional recommendation for whole-grain foods, i.e. 'favour their consumption among starchy foods when possible ${ }^{(6)}$.

The different categories of starchy foods carry varying concentrations of nutrients (e.g. vitamin $\mathrm{C}$ in potatoes, protein in legumes, and $\mathrm{Fe}$ and $\mathrm{B}$-vitamins in whole-grain products). Thus, diversity is of crucial importance. Choices in the types of starchy foods eaten may depend on cultural and generational factors. Cost may play a role in the choice of specific starchy food items such as high-quality breakfast cereals that may be more expensive. Nevertheless, the starchy food group is generally less costly than other food groups. This has been illustrated by Darmon et al. ${ }^{(7)}$, who reported that strengthening the cost constraint reduced the proportion of energy contributed by fruits and vegetables, meat and dairy products, and increased the proportion from cereal products, sweets and added fats.

Abbreviation: SU.VI.MAX, Supplémentation en VItamines Minéraux et AntioXydants.

The work was performed in UREN

* Corresponding author: Dr Mathilde Touvier, fax +331 483889 31, email m.touvier@uren.smbh.univ-paris13.fr 
Results are available concerning consumption of starchy foods and its association with sociodemographic and socioeconomic characteristics ${ }^{(8-20)}$. However, there is a dearth of information on the variety and types of starchy foods consumed. Nonetheless, such information would be useful for improving public health messages.

The aim of the present study was to investigate the links between sociodemographic and socioeconomic factors and compliance with recommendations, overall variety and distribution of cost across types of starchy foods. We used the definition of 'starchy food' which corresponds to that used in the French dietary guidelines ${ }^{(6)}$, i.e. potatoes, bread, pasta/semolina, rice, pulses, non-sugared breakfast cereals and other less frequently consumed starchy foods (tapioca, chestnuts, manioc, sweet potatoes, taros, ignam, starch and plantain). According to these official guidelines, sugared foods (such as sugary breakfast cereals, biscuits and cakes) are not considered starchy foods, but rather are classified into the 'sugary food' group, for which specific recommendations exist (i.e. 'limit consumption'). Our hypothesis was that all parameters of starchy food consumption were correlated with several sociodemographic and socioeconomic factors, and that these correlations vary across specific starchy food types.

\section{Methods}

\section{Study population}

We used data obtained from the 'Supplémentation en VItamines Minéraux et AntioXydants' (SU.VI.MAX) cohort, which is a large sample of middle-aged adults throughout France. The design, methods and rationale of the present study have been described elsewhere ${ }^{(21)}$. The SU.VI.MAX study was initially designed as a randomised, double-blind, placebo-controlled primary prevention trial to test the efficacy of daily supplementation with antioxidant vitamins and minerals at nutritional doses in reducing the incidence of IHD, cancers and overall mortality ${ }^{(22)}$. A total of 13017 subjects were included in 1994-5 for a planned follow-up of 8 years. They were volunteers recruited via a mass media campaign in 1994 and were not selected for specific risk factors. The present study was conducted according to the guidelines laid down in the Declaration of Helsinki, and all procedures involving human subjects were approved by the Ethical Committee for Studies with Human Subjects at the Paris-Cochin Hospital (CCPPRB no. 706) and the Commission Nationale Informatique et Liberté (CNIL no. 334641). Written informed consent was obtained from all subjects.

\section{Dietary assessment}

Dietary data were collected using the Minitel Telematic Network, which is a small terminal that was widely used as an adjunct to the telephone in France at the beginning of the study. Participants were invited to provide a 24-h dietary record every 2 months. These records were randomly distributed for two weekend days and four weekdays per year, so that each day of the week and all seasons were covered to account for individual variability in intake. At enrolment, participants received a tiny central processing unit specifically developed for the study and containing specialised software that allowed subjects to fill out the computerised dietary record off-line and to transmit data during brief telephone connections. Portion sizes were estimated using a validated picture booklet distributed to the participants at enrolment ${ }^{(23)}$. This manual included photographs of more than 250 foods (corresponding to 1000 generic foods) represented in three different portion sizes. Along with the two intermediate and two extreme quantities, there were seven choices of amounts. Edible amounts corresponding to each food had been validated previously in a pilot study ${ }^{(23)}$.

The nutritional values of the diet were estimated using a published French food composition table ${ }^{(24)}$. This database was completed by the unit cost of each food and beverage based on mean retail prices in France in 1997, which were obtained from marketing research and from the French National Institute of Statistics and Economic Studies. All values reported here are based on the mean daily dietary intake of each subject.

The whole-grain food group included whole-grain bread, pasta and rice. The 'whole-grain'-specific information was left to the subject's discretion. 'Whole-grain consumers' were defined as subjects who consumed at least the minimal amount of one serving of $50 \mathrm{~g}$ of total whole-grain foods during the course of the survey (i.e. summed up overall the dietary records). French recipes validated by food and nutrition professionals were used to assess the amounts consumed from composite foods.

\section{Sociodemographic and socioeconomic characteristics}

At enrolment, subjects were asked to fill in a self-administered questionnaire to provide sociodemographic and socioeconomic information. Level of education was recoded into three categories (from eight initial categories): elementary school, secondary school (junior and high school), and university or equivalent. The official French classification ${ }^{(25)}$ was used to classify subjects into occupational categories according to their self-reported occupation or most recent job if they were retired or unemployed. Occupational category was recoded into four categories (from nine initial categories) and a fifth corresponded to persons who had never worked. Marital status was recoded into two categories (from seven initial categories): living alone and cohabiting. The household location was classified into two categories (urban and rural) according to the definition of the French National Institute of Statistics and Economics Studies, which is based on both population density and economic activity of the area corresponding to each subject's zip code ${ }^{(26)}$.

\section{Statistical analyses}

We focused the present analyses on subjects aged 45-60 years who had completed at least six 24-h dietary records (some subjects had more than six records, with the median number of days of 24-h records being eleven, and the maximum being sixteen) during the first 2 years of followup (1995-7), and with available data for all sociodemographic and socioeconomic characteristics. As is the general rule in the SU.VI.MAX cohort ${ }^{(27)}$, we excluded dietary records that reported $<418.4 \mathrm{~kJ} / \mathrm{d}(100 \mathrm{kcal} / \mathrm{d})$ or $>25104 \mathrm{~kJ} / \mathrm{d}$ 
$(6000 \mathrm{kcal} / \mathrm{d})$ and we further excluded subjects who had $>2 / 3$ of their records that reported $<3347.2 \mathrm{~kJ} / \mathrm{d}(800 \mathrm{kcal} / \mathrm{d})$ in men and $<2092 \mathrm{~kJ} / \mathrm{d}(500 \mathrm{kcal} / \mathrm{d})$ in women. We translated the qualitative recommendation for starchy food intake (at each meal, according to appetite) into a quantitative criterion, i.e. $\geq 3$ and $<6$ servings/d, based on the usual number of meals per day (three to four), with some leeway for variation in appetite. One serving was defined as $200 \mathrm{~g}$ for cooked pasta/semolina, rice, pulses and 'other' starchy foods; $150 \mathrm{~g}$ for potatoes; $50 \mathrm{~g}$ for bread and $30 \mathrm{~g}$ for breakfast cereals (i.e. commonly used portion sizes for these foods $\left.{ }^{(6,28)}\right)$. Logistic regression analysis was used to assess sociodemographic and socioeconomic factors related to falling short of, or exceeding, the general starchy food recommendation (polytomic model ${ }^{(29)}$, common reference $=$ meeting the recommendation) and being a non-consumer of whole-grain foods (dichotomic model). Adjusted relative risk ratios for polytomic models, OR for dichotomic models and their $95 \% \mathrm{CI}$ are reported. Covariance analyses were performed to compare, across sociodemographic and socioeconomic categories, the number of different starchy foods (seven types, see above) reported during the survey (as a marker of variety) on the one hand, and the share of the starchy food budget devoted to each type of starchy food on the other hand. All multivariate models included sex, age, education level, occupational category, marital status, household location and total daily energy intake as covariates. Interactions with sex were tested, but none were statistically significant; thus, pooled analyses are presented in the present paper. Overall (for nominal variables, i.e. sex, occupational category, marital status and household location) and linear trend (for ordinal variables, i.e. age and education level) tests were performed. For all analyses, the significance level was two-sided and set at 0.05 , and all associations or differences mentioned throughout the paper were statistically significant at that level. All statistical analyses were performed using SAS software (version 9.1; SAS Institute, Inc., Cary, NC, USA).

\section{Results}

\section{Characteristics of the study population}

Among the 13017 participants in the SU.VI.MAX study, 6463 provided at least six valid 24-h dietary records during the first 2 years of follow-up; among them, 4941 were 45-60 years of age at inclusion. After exclusion of subjects with missing values for sociodemographic or socioeconomic variables, 4574 subjects remained for analysis. The amount of starchy foods provided by composite foods was $13.6 \%$. Whole-grain bread accounted for $10.4 \%$ of the total bread intake; wholegrain pasta, $2.7 \%$ of the total pasta intake; and whole-grain rice, $6.8 \%$ of the total rice intake (data not tabulated). For whole-grain consumers, bread represented an average of $80.0 \%$ of whole-grain foods, pasta $8.4 \%$ and rice $11.6 \%$ (data not tabulated). Sociodemographic and socioeconomic characteristics of the 4574 subjects, as well as adherence to the recommendations, are presented in Table 1, and starchy food intake is described in Table 2. About $55 \%$ of the population met the general starchy food recommendation,
Table 1. Sociodemographic and socioeconomic characteristics in the studied population and adherence to national French recommendations* ( $n$ 4574), Supplémentation en VItamines Minéraux et AntioXydants cohort, 1995-7

(Number of subjects and percentages)

\begin{tabular}{lcr}
\hline & $n$ & $\%$ \\
\hline Sex & & \\
$\quad$ Men & 2503 & $54 \cdot 7$ \\
$\quad$ Women & 2071 & $45 \cdot 3$ \\
Age (years) & & \\
$\quad 45-49$ & 1866 & $40 \cdot 8$ \\
$50-54$ & 1439 & $31 \cdot 5$ \\
$\quad 55-60$ & 1269 & $27 \cdot 7$ \\
Education level & & \\
$\quad$ Elementary school & 1016 & $22 \cdot 2$ \\
$\quad$ Secondary school & 1805 & $39 \cdot 5$ \\
$\quad$ University or equivalent & 1753 & $38 \cdot 3$ \\
Occupational category & & \\
$\quad$ Managerial staff & 1419 & $31 \cdot 0$ \\
$\quad$ Self-employed, farmers & 226 & $4 \cdot 9$ \\
$\quad$ Intermediate professions, employees & 2479 & $54 \cdot 2$ \\
$\quad$ Manual workers & 214 & $4 \cdot 7$ \\
$\quad$ Never employed & 236 & $5 \cdot 2$ \\
Marital status & & \\
$\quad$ Living alone & 633 & $13 \cdot 8$ \\
$\quad$ Cohabiting & 3941 & $86 \cdot 2$ \\
Household location & & \\
$\quad$ Urban & 3844 & $84 \cdot 0$ \\
$\quad$ Rural & 730 & $16 \cdot 0$ \\
Mean number of servings of starchy foods per day & \\
$\quad<3$ & 1638 & $35 \cdot 8$ \\
$\quad$ Z 3 and <6 & 2501 & $54 \cdot 7$ \\
$\quad$ W 6 & 435 & $9 \cdot 5$ \\
Whole-grain food consumption (bread, pasta and rice) & \\
$\quad$ No & 2596 & $56 \cdot 8$ \\
$\quad$ Yes & 1978 & $43 \cdot 2$ \\
\hline
\end{tabular}

* Recommendations of the 'Programme National Nutrition Santé' for 2001-10: (1) 'starchy foods: at each meal, according to appetite', translated as ' $\geq 3$ and $<6$ ' for the evaluation; (2) 'whole-grain foods: favour their consumption among starchy foods when possible'. Sugared foods such as sugary breakfast cereals are not considered starchy foods.

while $35.8 \%$ fell short of it and $9.5 \%$ were above it. The proportion of whole-grain product consumers was $43.2 \%$.

\section{Adherence to recommendations according to sociodemographic and socioeconomic characteristics}

Women were less likely to exceed the recommendation for starchy foods than men (Table 3).

Non-consumption of whole-grain products was associated with lower education level and was more frequent in men than in women (Table 3). Compared to managerial staff, selfemployed/farmers and intermediate professions/employees were more likely to be non-consumers of whole-grain products.

\section{Variety and types of starchy foods consumed}

After adjustment for the number of dietary records provided by the subjects, the number of different starchy foods consumed during the survey (as a marker of variety) increased with education level $(P=0 \cdot 0002)$ and was lowest for manual workers $(P=0.03)$ (data not tabulated). The starchy food cost was higher in men, in older subjects and in rural areas, 
Table 2. Starchy food intake characteristics in the studied population ( $n$ 4574)

(Mean values and standard deviations)

\begin{tabular}{|c|c|c|}
\hline & Mean & SD \\
\hline Total energy intake* $(\mathrm{kJ} / \mathrm{d})$ & $9153 \cdot 1$ & $2551 \cdot 6$ \\
\hline $\begin{array}{l}\text { Proportion of energy intake provided by } \\
\text { starchy foods (\%) }\end{array}$ & $24 \cdot 0$ & 6.6 \\
\hline \multicolumn{3}{|l|}{ Variety of food consumed } \\
\hline Daily starchy food intake $(\mathrm{g} / \mathrm{d})$ & $286 \cdot 6$ & $121 \cdot 2$ \\
\hline $\begin{array}{l}\text { Number of servings of starchy foods } \\
\text { per day† }\end{array}$ & $3 \cdot 8$ & $1 \cdot 7$ \\
\hline \multicolumn{3}{|l|}{ Potatoes } \\
\hline Percentage of starchy food intake & $26 \cdot 6$ & $13 \cdot 6$ \\
\hline Number of servings per day & 0.5 & 0.4 \\
\hline \multicolumn{3}{|l|}{ Bread } \\
\hline Percentage of starchy food intake & 44.6 & $15 \cdot 1$ \\
\hline Number of servings per day - refined & $2 \cdot 3$ & 1.4 \\
\hline Number of servings per day - whole-grain & 0.2 & 0.5 \\
\hline \multicolumn{3}{|l|}{ Pasta and semolina } \\
\hline Percentage of starchy food intake & $12 \cdot 7$ & $10 \cdot 2$ \\
\hline Number of servings per day - refined & 0.2 & 0.2 \\
\hline Number of servings per day - whole-grain & 0.01 & 0.03 \\
\hline \multicolumn{3}{|l|}{ Rice } \\
\hline Percentage of starchy food intake & $7 \cdot 6$ & $8 \cdot 2$ \\
\hline Number of servings per day - refined & 0.1 & $0 \cdot 1$ \\
\hline Number of servings per day - whole-grain & 0.01 & 0.04 \\
\hline \multicolumn{3}{|l|}{ Pulses } \\
\hline Percentage of starchy food intake & $4 \cdot 3$ & $6 \cdot 1$ \\
\hline Number of servings per day & 0.1 & $0 \cdot 1$ \\
\hline \multicolumn{3}{|l|}{ Breakfast cereals (without added sugar) } \\
\hline Percentage of starchy food intake & $2 \cdot 4$ & 5.9 \\
\hline Number of servings per day & 0.2 & 0.5 \\
\hline \multicolumn{3}{|l|}{ Other starchy foods $\ddagger$} \\
\hline Percentage of starchy food intake & 1.8 & $2 \cdot 4$ \\
\hline Number of servings per day & $0 \cdot 1$ & $0 \cdot 1$ \\
\hline $\begin{array}{l}\text { Number of different starchy foods reported } \\
\text { during the survey§ }\end{array}$ & $5 \cdot 3$ & $1 \cdot 1$ \\
\hline \multicolumn{3}{|l|}{ Daily costs $(€ / \mathrm{d}) \|$} \\
\hline Total daily food cost & $5 \cdot 8$ & 1.8 \\
\hline Total daily starchy food cost & 0.5 & 0.2 \\
\hline
\end{tabular}

*Including alcohol.

†One serving was defined as $200 \mathrm{~g}$ for cooked pasta/semolina, rice, pulses and other starchy foods; $150 \mathrm{~g}$ for potatoes; $50 \mathrm{~g}$ for bread and $30 \mathrm{~g}$ for breakfast cereals.

$\ddagger$ Tapioca, chestnuts, manioc, sweet potatoes, taros, ignam, starch and plantain. $\S$ The seven different categories of starchy foods were potatoes, bread, pasta/semolina, rice, pulses, unsweetened breakfast cereals and other starchy foods. The median number of days of dietary record was eleven.

|| Including alcoholic and non-alcoholic beverages. $1 €=1.37$ US $\$$ (as of 12 May 2009).

and was inversely associated with occupational category (Table 4). In men, the daily cost for potatoes, pasta/semolina, rice and pulses was higher than in women, and it was lower for bread and other starchy foods. The proportion of the starchy food cost devoted to pasta/semolina decreased with age, while that devoted to other starchy foods increased with age. The portion of the starchy food cost devoted to potatoes decreased with education level, while that devoted to rice and unsweetened breakfast cereals increased with education level.

\section{Discussion}

In our population-based study conducted in 1995-7, about $55 \%$ of subjects complied with the starchy food recommendation, $36 \%$ fell short of it and $9.5 \%$ exceeded it.
Dietary information dating from that period, i.e. the mid/late $90 \mathrm{~s}$, is of interest. Indeed, before the start of the French Nutrition and Health Programme in 2001, nutritional messages were not widespread, and recommendations reached only those who sought them out. Moreover, starchy foods were generally negatively perceived as being 'stodgy'. Since 2001, due to intensive media campaigns, several health and nutritional messages have become familiar to the general French population. A new challenge lies in the ability to understand and make use of such messages. Nevertheless, up until now, advice concerning starchy foods was not widespread. Its diffusion (conveyed by television advertisements) began in 2008 and will increase in the near future, justifying the importance of historical data on consumption of these products and identification of sociodemographic and socioeconomic factors associated with quality and variety.

In the recent national nutrition and health survey (Étude Nationale Nutrition Santé; ENNS, 2006-7) ${ }^{(28)}$ based on a representative sample of the French population, $47 \%$ of subjects in the same age group (45-60 years old) complied with the starchy food recommendation, $44 \%$ fell below it and $9 \%$ were above it. The differences observed between the two studies could be interpreted as a 10-year evolution in compliance with starchy food recommendations. However, caution is needed when interpreting this comparison. Indeed, our subjects were volunteers participating in a nutritional intervention study ${ }^{(22)}$ who generally had a higher education level and occupational status, along with a healthier diet, than the general population. Furthermore, a bias might lie in overreporting of healthy food items (such as whole-grain products) among those with a higher education level, as was observed for fruits and vegetables $^{(30)}$. Nevertheless, the selection of at least six 24 -h dietary records over a 2-year period represents one strength of the present study, as it enabled reliable diet estimation and limited misclassification by decreasing intra-individual variations ${ }^{(31)}$. Low intake with respect to recommendations for starchy foods ${ }^{(8,32,33)}$, bread $^{(34)}$ and pulses ${ }^{(8,35,36)}$ had also been reported previously in other countries.

In the present study, men were more likely than women to exceed the starchy food recommendation (16v. 2\%), which was in agreement with the literature that reported higher starchy food intake in men ${ }^{(20)}$.

This result could be partly explained by the fact that identical serving sizes were used for men and women in order to be consistent with the official French recommendation, which does not mention any difference in serving size between sexes. However, this finding was statistically significant even after adjustment for total energy intake. Excessive intake should therefore be monitored in men. However, on the whole, only about $9 \%$ of subjects exceeded the recommendation in our population, as in the ENNS study. This percentage was far lower than that observed in the same population for animal products (about $30 \%$ for meat/ seafood/eggs; data not shown). This suggests that avoiding excessive intake of starchy foods is less crucial than for other food groups. Indeed, in the age range examined here, increasing the daily consumption of these sources of complex carbohydrates with good satiating properties ${ }^{(3)}$ remains the main objective.

Nutritional values of the different starchy foods are complementary. Therefore, the national recommendation for 
Table 3. Compliance with the starchy food recommendation and whole-grain food (bread, pasta and rice) consumption according to sociodemographic and socioeconomic characteristics ( $n$ 4574)*

(Relative risk ratios (RRR), odds ratios and $95 \%$ confidence intervals)

\begin{tabular}{|c|c|c|c|c|c|c|c|c|}
\hline & \multicolumn{2}{|c|}{$\begin{array}{l}\text { Below } v \text {. meeting } \\
\text { the starchy food } \\
\text { recommendation } †\end{array}$} & \multicolumn{3}{|c|}{$\begin{array}{l}\text { Above } v \text {. meeting the starchy } \\
\text { food recommendationt }\end{array}$} & \multicolumn{3}{|c|}{$\begin{array}{c}\text { Non-consumer } v \text {. consumer of } \\
\text { whole-grain foods } \ddagger\end{array}$} \\
\hline & RRR & $95 \% \mathrm{Cl}$ & RRR & $95 \% \mathrm{Cl}$ & $P \S$ & OR & $95 \% \mathrm{Cl}$ & $P \S$ \\
\hline Sex & & & & & 0.001 & & & 0.001 \\
\hline Male & 1.00 & & 1.00 & & & 1.00 & & \\
\hline Female & $1 \cdot 15$ & $0.96,1.38$ & 0.48 & $0.31,0.74$ & & 0.79 & $0.68,0.91$ & \\
\hline Age (years) & & & & & 0.05 & & & 0.8 \\
\hline $45-49$ & 1.00 & & 1.00 & & & 1.00 & & \\
\hline $50-54$ & 1.00 & $0.84,1.20$ & 0.90 & $0.67,1.21$ & & $1 \cdot 12$ & $0.97,1.28$ & \\
\hline $55-60$ & 0.77 & $0.64,0.94$ & 0.99 & $0.74,1.33$ & & 1.01 & $0.87,1.17$ & \\
\hline Education level & & & & & 0.7 & & & 0.01 \\
\hline Elementary school & 1.00 & & 1.00 & & & 1.00 & & \\
\hline Secondary school & 1.00 & $0.81,1.24$ & 0.88 & $0.64,1.22$ & & 0.96 & $0.82,1.14$ & \\
\hline University or equivalent & 1.08 & $0.86,1.37$ & 0.91 & $0.63,1.31$ & & 0.81 & $0.68,0.97$ & \\
\hline Occupational category & & & & & 0.1 & & & 0.02 \\
\hline Managerial staff & 1.00 & & 1.00 & & & 1.00 & & \\
\hline Self-employed, farmers & 0.91 & $0.61,1.36$ & 1.66 & $0.96,2.89$ & & 1.57 & $1 \cdot 15,2 \cdot 14$ & \\
\hline Intermediate professions, employees & 0.82 & $0.67,1.01$ & $1 \cdot 15$ & $0.85,1.56$ & & 1.19 & $1.02,1.38$ & \\
\hline Manual workers & 0.87 & $0.56,1.36$ & 1.91 & $1 \cdot 13,3.23$ & & 1.24 & $0.90,1.72$ & \\
\hline Never employed & 0.71 & $0.49,1.02$ & 1.32 & $0.45,3.90$ & & 1.01 & $0.75,1.37$ & \\
\hline Marital status & & & & & 0.4 & & & 0.1 \\
\hline Living alone & 1.00 & & 1.00 & & & 1.00 & & \\
\hline Cohabiting & 1.00 & $0.80,1.25$ & 1.34 & $0.88,2.04$ & & 1.14 & $0.96,1.35$ & \\
\hline Household location & & & & & 0.1 & & & 0.5 \\
\hline Rural & 1.00 & & 1.00 & & & 1.00 & & \\
\hline Urban & 1.25 & $1.01,1.56$ & 1.01 & $0.73,1.39$ & & 1.05 & $0.89,1.24$ & \\
\hline
\end{tabular}

starchy foods is accompanied by advice on variety ${ }^{(6)}$. We found very little literature that had examined variety in starchy food consumption ${ }^{(37,38)}$, and to our knowledge, none provided details on differences in starchy food variety according to sociodemographic and socioeconomic characteristics. In the present study, the diversity of starchy food intake increased with education level and was lowest for manual workers, which is in accordance with previously published results on variety in fruits and vegetables ${ }^{(39)}$ and diet as a whole ${ }^{(38)}$.

Generally speaking, starchy foods are relatively inexpensive. Indeed, they represented only $8.6 \%$ of the total daily food cost in the present study, while they provided an average of about a quarter of the total energy intake. The fact that starchy foods are an inexpensive source of energy could partly explain the observed inverse gradient between occupational category and the proportion of the food budget devoted to starchy foods. It might be hypothesised that the satiety:cost ratio of the starchy food group is particularly appreciated by disadvantaged subjects. In line with previously published findings, we observed that subjects with a higher education level spent more on 'modern' foods such as highquality breakfast cereals (without added sugar) ${ }^{(9,14,17)}$ and rice $^{(14)}$, but less on traditionally recommended foods such as potatoes ${ }^{(8,15)}$. As starchy foods are usually low-priced, it was not surprising to observe cost differences of only a few cents in the present study. However, a slight difference of only $0.3 € / d$ represents $3 € /$ month. In a household of four persons, for example, this could reach $3 \times 4=12 € /$ month, which is not to be ignored in the food budget of relatively low-income families, especially considering that this is only part of the overall cost-related food pattern. Further information (unavailable in the present study) on preparation of starchy foods (addition of fats, salt, salsa, etc.) would be of interest, as this could influence the relationship between types of starchy foods consumed and sociodemographic and socioeconomic factors.

Thus far, starchy foods have had a rather negative and fattening image. Women, who are generally more concerned about their weight, spent less on potatoes, pasta/semolina, rice and pulses than men, which is in agreement with the literature $^{(20)}$. Other factors (culture, generation and social context) may explain disparities in the types of starchy foods consumed by the different sociodemographic categories, as previously shown for fruits and vegetables ${ }^{(40)}$. In contrast, availability is probably not a strong determinant of starchy food consumption due to a longer shelf life and ease of storage of such food products.

The present results showing higher whole-grain food consumption in women ${ }^{(12,18)}$ and in subjects with higher education levels ${ }^{(14,18)}$ and occupational categories ${ }^{(10,11,18,19)}$ are in accordance with the literature and with the healthy image of these foods. Low whole-grain food intake has been reported previously in many countries ${ }^{(19,35,41)}$. Despite a minor restrictive criterion for whole-grain consumers, only 
Table 4. Distribution of starchy food cost across types of starchy foods according to sociodemographic and socioeconomic characteristics $(n 4574)^{*}$

\begin{tabular}{|c|c|c|c|c|c|c|c|c|}
\hline & \multirow[b]{2}{*}{$\begin{array}{l}\text { Daily starchy } \\
\text { food cost }(€ / d)\end{array}$} & \multicolumn{7}{|c|}{ Distribution of daily starchy food cost (\%) } \\
\hline & & Potatoes & Bread & $\begin{array}{l}\text { Pasta/ } \\
\text { semolina }\end{array}$ & Rice & Pulses & $\begin{array}{l}\text { Breakfast } \\
\text { cereals }\end{array}$ & $\begin{array}{l}\text { Other starchy } \\
\text { foods } \ddagger\end{array}$ \\
\hline \multicolumn{9}{|l|}{ Sex } \\
\hline Male & 0.52 & 14.51 & 65.99 & 4.45 & $2 \cdot 60$ & 4.83 & 4.43 & $3 \cdot 18$ \\
\hline Female & 0.51 & 13.37 & $68 \cdot 31$ & 3.24 & $2 \cdot 22$ & 4.33 & 4.47 & 4.07 \\
\hline$P$ & 0.03 & 0.0005 & $<0.0001$ & $<0.0001$ & 0.0009 & 0.03 & 0.9 & $<0.0001$ \\
\hline \multicolumn{9}{|l|}{ Age (years) } \\
\hline $45-49$ & 0.51 & 13.66 & $67 \cdot 21$ & $4 \cdot 12$ & 2.44 & 4.58 & 4.73 & 3.26 \\
\hline $50-54$ & 0.50 & $14 \cdot 15$ & $66 \cdot 75$ & 3.83 & $2 \cdot 46$ & 4.73 & 4.58 & 3.50 \\
\hline $55-60$ & 0.53 & 14.02 & $67 \cdot 48$ & 3.58 & $2 \cdot 33$ & 4.43 & 4.05 & 4.11 \\
\hline$P$-trend & $<0.0001$ & 0.2 & 0.7 & 0.0001 & 0.3 & 0.6 & 0.09 & $<0.0001$ \\
\hline \multicolumn{9}{|l|}{ Education level } \\
\hline Elementary school & 0.51 & 14.53 & $67 \cdot 41$ & 3.92 & $2 \cdot 22$ & 4.59 & 3.70 & 3.64 \\
\hline Secondary school & 0.52 & 13.84 & $67 \cdot 30$ & 3.84 & $2 \cdot 33$ & 4.63 & 4.44 & 3.61 \\
\hline University or equivalent & 0.52 & 13.45 & $66 \cdot 73$ & 3.77 & $2 \cdot 67$ & 4.52 & 5.22 & 3.63 \\
\hline$P$-trend & 0.7 & 0.007 & 0.3 & 0.4 & 0.001 & 0.8 & 0.001 & 0.98 \\
\hline \multicolumn{9}{|l|}{ Occupational category } \\
\hline Managerial staff & 0.49 & 13.55 & $67 \cdot 29$ & 3.91 & 2.39 & 4.31 & $5 \cdot 28$ & $3 \cdot 27$ \\
\hline Self-employed, farmers & 0.51 & $14 \cdot 26$ & 66.85 & 3.80 & $2 \cdot 23$ & 5.14 & 3.69 & 4.03 \\
\hline Intermediate professions, employees & 0.51 & 13.87 & $67 \cdot 12$ & 3.72 & 2.39 & 4.53 & 4.76 & 3.62 \\
\hline Manual workers & 0.53 & $14 \cdot 32$ & 66.98 & 4.02 & 2.55 & 4.52 & 4.26 & 3.36 \\
\hline Never employed & 0.54 & 13.71 & $67 \cdot 50$ & 3.77 & 2.49 & 4.40 & 4.28 & 3.86 \\
\hline$P$ & 0.0004 & 0.7 & 0.99 & 0.7 & 0.8 & 0.5 & 0.3 & 0.06 \\
\hline \multicolumn{9}{|l|}{ Marital status } \\
\hline Living alone & 0.51 & 13.73 & $66 \cdot 73$ & 3.92 & 2.51 & 4.84 & 4.66 & 3.62 \\
\hline Cohabiting & 0.52 & $14 \cdot 16$ & 67.56 & 3.77 & $2 \cdot 31$ & 4.32 & 4.25 & 3.63 \\
\hline$P$ & 0.4 & 0.2 & 0.2 & 0.4 & 0.1 & 0.06 & 0.4 & 0.96 \\
\hline \multicolumn{9}{|l|}{ Household location } \\
\hline Rural & 0.53 & $14 \cdot 22$ & 66.89 & 3.78 & 2.43 & 4.60 & 4.33 & 3.76 \\
\hline Urban & 0.51 & 13.66 & $67 \cdot 41$ & 3.91 & 2.39 & 4.56 & 4.58 & 3.50 \\
\hline$P$ & 0.002 & 0.1 & 0.4 & 0.5 & 0.8 & 0.9 & 0.6 & 0.1 \\
\hline
\end{tabular}

*Variables included in the ANOVA models were sex, age, education level, occupational category, marital status, household location and total daily energy intake. $\dagger 1 €=1.37$ US $\$$ (as of 12 May 2009).

$\ddagger$ Tapioca, chestnuts, manioc, sweet potatoes, taros, ignam, starch and plantain.

$43 \%$ of our subjects were consumers of whole-grain bread, pasta or rice. However, we did not include whole-grain breakfast cereals in our analyses of whole-grain foods since the whole-grain-specific information was not available for these products in the present study. In addition, in France, according to official legislation, 'whole-grain bread', 'wholegrain pasta' and 'whole-grain rice' designate foods prepared with $100 \%$ whole-grain ingredients. Therefore, since the whole-grain specification was left to the subject's discretion in the present study, the consumption of partially wholegrain foods (e.g. bread with $50 \%$ of whole meal starch) may have been underestimated. Moreover, since 1995-7, availability of whole-grain pasta and rice has increased; thus, the corresponding prevalence may currently be higher. A limitation of the present study was that participants with few records had a less chance to meet the 'whole-grain criterion'. However, subjects who did not even consume at least $50 \mathrm{~g}$ whole-grain foods during $6 \mathrm{~d}$ were in any case poor consumers. Besides, the prevalence of whole-grain consumption was close in subjects with number of records below and above the median (41 and $45 \%$, respectively, data not shown). Finally, analysis performed to investigate characteristics associated with whole-grain consumption was adjusted for the number of dietary records.

There is a consistent inverse association between wholegrain products and several chronic diseases in epidemiological studies ${ }^{(1-3)}$. Therefore, policy makers, scientists and clinicians should intensify efforts to include clear messages on the beneficial effects of whole-grain foods in public health measures and clinical practice. While awareness of the health benefits of whole-grain foods is on the increase, classification and identification of these foods at the point of purchase may represent major barriers to attaining daily recommended levels of whole-grain intake ${ }^{(42)}$.

Specific and strategic stakes for the starchy food group include variety, priority given to whole-grain products and the need to increase overall consumption within the limits of the recommendations. In this context, the present study provides original data on determinants of starchy food consumption in a large general population, simultaneously taking into account occupational category and education level in addition to other sociodemographic factors, as recommended ${ }^{(43-45)}$. Further information on identification of whole-grain products and related health benefits, as well as development of diversified, tasty, low-cost, easy-to-prepare pulses and whole-grain foods, could significantly improve the quality and variety of starchy food intake. The ongoing French Nutrition and Health Programme, as well as similar public health plans worldwide, would benefit from a better understanding of the influence of budgetary constraints, nutritional awareness, social context and environmental barriers upon food choices. This should help to more efficiently elaborate measures for improving behaviours implicated in chronic disease risk. 


\section{Acknowledgements}

The present work was supported by the French National Research Agency (Agence Nationale de la Recherche) in the context of the 2005 Programme National de Recherche en Alimentation et Nutrition Humaine (ANR-05-PNRA-012). None of the authors had a conflict of interest. M. T. designed the study, analysed and interpreted data and wrote the manuscript. C. M., E. K.-G., A.-C. V. and S. P. contributed to interpreting results and editing the manuscript. S. H. designed and coordinated the study cohort and supervised the study. K. C. supervised the design and interpretation of data as well as the writing of the manuscript. All authors reviewed the manuscript. We thank all scientists who helped to carry out the SU.VI.MAX study, the teams that assisted in fieldwork and the dedicated and conscientious volunteers who participated in this cohort. We are grateful to Jerri Bram for revising the manuscript.

\section{References}

1. American Institute for Cancer Research/World Cancer Research Fund (2007) Food, Nutrition, Physical Activity and the Prevention of Cancer: A Global Perspective. Washington, DC: American Institute for Cancer Research.

2. World Health Organization (2003) Diet, Nutrition and the Prevention of Chronic Diseases. Joint WHO/FAO Expert Consultation. WHO Technical Report Series no. 916. Geneva: WHO.

3. World Health Organization (2007) The Challenge of Obesity in the WHO European Region and the Strategies for Response. Copenhagen: WHO Regional Office for Europe.

4. Lachat C, Van Camp J, De Henauw S, et al. (2005) A concise overview of national nutrition action plans in the European Union Member States. Public Health Nutr 8, 266-274.

5. Estaquio C, Kesse-Guyot E, Deschamps V, et al. (2009) Adherence to the French Programme National Nutrition Santé Guideline Score is associated with better nutrient intake and nutritional status. J Am Diet Assoc 109, 1031-1041.

6. Hercberg S, Chat-Yung S \& Chauliac M (2008) The French National Nutrition and Health Program: 2001-2006-2010. Int J Public Health 53, 68-77.

7. Darmon N, Ferguson EL \& Briend A (2002) A cost constraint alone has adverse effects on food selection and nutrient density: an analysis of human diets by linear programming. J Nutr 132, 3764-3771.

8. Aranceta J (2001) Spanish food patterns. Public Health Nutr 4, $1399-1402$.

9. Deshmukh-Taskar P, Nicklas TA, Yang SJ, et al. (2007) Does food group consumption vary by differences in socioeconomic, demographic, and lifestyle factors in young adults? The Bogalusa Heart Study. J Am Diet Assoc 107, 223-234.

10. Dowler E (2001) Inequalities in diet and physical activity in Europe. Public Health Nutr 4, 701-709.

11. James WP, Nelson M, Ralph A, et al. (1997) Socioeconomic determinants of health. The contribution of nutrition to inequalities in health. BMJ 314, 1545-1549.

12. McNaughton SA, Ball K, Crawford D, et al. (2008) An index of diet and eating patterns is a valid measure of diet quality in an Australian population. $J$ Nutr 138, 86-93.

13. Moreira PA \& Padrao PD (2004) Educational and economic determinants of food intake in Portuguese adults: a crosssectional survey. BMC Public Health 4, 58.
14. Northstone K, Emmett P \& Rogers I (2008) Dietary patterns in pregnancy and associations with socio-demographic and lifestyle factors. Eur J Clin Nutr 62, 471-479.

15. Perrin AE, Dallongeville J, Ducimetiere P, et al. (2005) Interactions between traditional regional determinants and socio-economic status on dietary patterns in a sample of French men. Br J Nutr 93, 109-114.

16. Roos E, Prattala R, Lahelma E, et al. (1996) Modern and healthy?: socioeconomic differences in the quality of diet. Eur J Clin Nutr 50, 753-760.

17. Siega-Riz AM, Popkin BM \& Carson T (2000) Differences in food patterns at breakfast by sociodemographic characteristics among a nationally representative sample of adults in the United States. Prev Med 30, 415-424.

18. Steele P, Dobson A, Alexander H, et al. (1991) Who eats what? A comparison of dietary patterns among men and women in different occupational groups. Aust J Public Health 15, 286-295.

19. Thane CW, Jones AR, Stephen AM, et al. (2007) Comparative whole-grain intake of British adults in 1986-7 and 2000-1. Br J Nutr 97, 987-992.

20. Vandevijvere S, De Vriese S, Huybrechts I, et al. (2009) The gap between food-based dietary guidelines and usual food consumption in Belgium, 2004. Public Health Nutr 12, $423-431$.

21. Hercberg S, Preziosi P, Briancon S, et al. (1998) A primary prevention trial using nutritional doses of antioxidant vitamins and minerals in cardiovascular diseases and cancers in a general population: the SU.VI.MAX study-design, methods, and participant characteristics. SUpplementation en VItamines et Mineraux AntioXydants. Control Clin Trials 19, 336-351.

22. Hercberg S, Galan P, Preziosi P, et al. (2004) The SU.VI.MAX study: a randomized, placebo-controlled trial of the health effects of antioxidant vitamins and minerals. Arch Intern Med 164, 2335-2342.

23. Le Moullec N, Deheeger M, Preziosi P, et al. (1996) Validation du manuel photos utilisé pour l'enquête alimentaire de l'étude SU.VI.MAX (Validation of the picture booklet used in the SU.VI.MAX study for the estimation of food portion sizes). Cah Nutr Diet 31, 158-164.

24. Hercberg S (coordinator) (2005) Table de Composition SU.VI.MAX des Aliments (Table of Food Composition SU.VI.MAX). Paris: Les éditions INSERM/Economica.

25. INSEE (2009) National Institute for Statistics and Economic Studies - Les nomenclatures des professions et catégories socioprofessionnelles (Lexicon for occupational categories). http://www.insee.fr/fr/nom_def_met/nomenclatures/pcs.htm (accessed 3 January 2009).

26. T LeJeannic \& J Vidalenc (1997) Pôles Urbains et Périurbanisation - Le Zonage en Aires Urbaines (Urban and Periurban Zoning - The Zoning in Urban Areas). Paris: INSEE Première.

27. Lairon D, Arnault N, Bertrais S, et al. (2005) Dietary fiber intake and risk factors for cardiovascular disease in French adults. Am J Clin Nutr 82, 1185-1194.

28. Castetbon K, Vernay M, Malon A, et al. (2009) Dietary intake, physical activity and nutritional status in adults: the French nutrition and health survey (ENNS, 2006-2007). Br J Nutr $1-11$.

29. Hosmer DW \& Lemeshow S (2000) Applied Logistic Regression. New York: Wiley Series in Probability and Mathematical Statistics.

30. Irala-Estevez JD, Groth M, Johansson L, et al. (2000) A systematic review of socio-economic differences in food habits in Europe: consumption of fruit and vegetables. Eur $J$ Clin Nutr 54, 706-714.

31. Margetts BM \& Nelson M (1997) Design Concepts in Nutritional Epidemiology, 2nd ed. Oxford: Oxford University Press. 
32. Lean ME, Anderson AS, Morrison C, et al. (2003) Evaluation of a dietary targets monitor. Eur J Clin Nutr 57, 667-673.

33. Serra ML, Ribas BL, Perez RC, et al. (2003) Dietary habits and food consumption in Spanish children and adolescents (1998-2000): socioeconomic and demographic factors. Med Clin (Barc) 121, 126-131.

34. Ball K, Mishra GD, Thane CW, et al. (2004) How well do Australian women comply with dietary guidelines? Public Health Nutr 7, 443-452.

35. Bachman JL, Reedy J, Subar AF, et al. (2008) Sources of food group intakes among the US population, 2001-2002. J Am Diet Assoc 108, 804-814.

36. Mitchell DC, Lawrence FR, Hartman TJ, et al. (2009) Consumption of dry beans, peas, and lentils could improve diet quality in the US population. $J$ Am Diet Assoc 109, 909-913.

37. Azadbakht L, Mirmiran P \& Azizi F (2005) Variety scores of food groups contribute to the specific nutrient adequacy in Tehranian men. Eur J Clin Nutr 59, 1233-1240.

38. Slattery ML, Berry TD, Potter J, et al. (1997) Diet diversity, diet composition, and risk of colon cancer (United States). Cancer Causes Control 8, 872-882.

39. Estaquio C, Druesne-Pecollo N, Latino-Martel P, et al. (2008) Socioeconomic differences in fruit and vegetable consumption among middle-aged French adults: adherence to the 5 A Day recommendation. J Am Diet Assoc 108, 2021-2030.

40. Sorensen G, Stoddard AM, Dubowitz T, et al. (2007) The influence of social context on changes in fruit and vegetable consumption: results of the healthy directions studies. Am J Public Health 97, 1216-1227.

41. Cleveland LE, Moshfegh AJ, Albertson AM, et al. (2000) Dietary intake of whole grains. $J$ Am Coll Nutr 19, 331S-338S

42. Burgess-Champoux TL, Rosen R, Marquart L, et al. (2008) The development of psychosocial measures for whole-grain intake among children and their parents. J Am Diet Assoc 108, 714-717.

43. Galobardes B, Morabia A \& Bernstein MS (2001) Diet and socioeconomic position: does the use of different indicators matter? Int J Epidemiol 30, 334-340.

44. Lallukka T, Laaksonen M, Rahkonen O, et al. (2007) Multiple socio-economic circumstances and healthy food habits. Eur $J$ Clin Nutr 61, 701-710.

45. Turrell G, Hewitt B, Patterson C, et al. (2003) Measuring socio-economic position in dietary research: is choice of socio-economic indicator important? Public Health Nutr 6, 191-200. 